\title{
Correction to: Dietary practices of soccer athletes registered at the University of Limpopo, Limpopo Province, South Africa
}

\author{
S. Masoga ${ }^{1} \oplus \cdot$ M. T. Maja $^{1} \cdot$ M. P. Matsepane ${ }^{1} \cdot$ S. C. Sethemane ${ }^{1}$
}

Published online: 26 February 2022

C) Springer-Verlag Italia S.r.l., part of Springer Nature 2022

\section{Correction to: Sport Sciences for Health https://doi.org/10.1007/s11332-021-00790-3}

Publisher's Note Springer Nature remains neutral with regard to jurisdictional claims in published maps and institutional affiliations.

The affiliation of Masoga S., Maja M.T., Matsepane M.P. and Sethemane S.C. was incorrectly published in the original publication. The complete correct affiliation of these authors are given below.

Department of Human Nutrition and Dietetics; University of Limpopo, Sovenga, Polokwane, 0727. South Africa.

The original article can be found online at https://doi.org/10.1007/ s11332-021-00790-3.

S. Masoga

sylven.masoga@ul.ac.za

M. T. Maja

matsobanemahlako@gmail.com

M. P. Matsepane

mashidikanepercy@gmail.com

S. C. Sethemane

sethemanesesekwa@gmail.com

1 Department of Human Nutrition and Dietetics, University

of Limpopo, Sovenga, Polokwane 0727, South Africa 